

\title{
High temperature compression behavior of the solid phase resulting from drained compression of a semi-solid 6061 alloy
}

\author{
Eliane Giraud, Michel Suery, Michel Coret
}

\section{- To cite this version:}

Eliane Giraud, Michel Suery, Michel Coret. High temperature compression behavior of the solid phase resulting from drained compression of a semi-solid 6061 alloy. Materials Science and Engineering: A, 2012, 532, pp.37-43. 10.1016/j.msea.2011.10.059 . hal-01006927

\section{HAL Id: hal-01006927 \\ https://hal.science/hal-01006927}

Submitted on 1 Apr 2018

HAL is a multi-disciplinary open access archive for the deposit and dissemination of scientific research documents, whether they are published or not. The documents may come from teaching and research institutions in France or abroad, or from public or private research centers.
L'archive ouverte pluridisciplinaire HAL, est destinée au dépôt et à la diffusion de documents scientifiques de niveau recherche, publiés ou non, émanant des établissements d'enseignement et de recherche français ou étrangers, des laboratoires publics ou privés. 


\title{
High temperature compression behavior of the solid phase resulting from drained compression of a semi-solid 6061 alloy
}

\author{
E. Giraud ${ }^{\mathrm{a}, *}$, M. Suéry ${ }^{\mathrm{a}}, \mathrm{M}$. Coret ${ }^{\mathrm{b}}$ \\ a Université de Grenoble, SIMaP/GPM2, UMR CNRS 5266, Grenoble INP, UJF, BP46, Domaine universitaire, 38402 Saint Martin d'Hères Cedex, France \\ ${ }^{\mathrm{b}}$ Université de Lyon, LaMCOS, UMR CNRS 5514, INSA-Lyon, 20, Avenue Albert Einstein, 69621 Villeurbanne, France
}

\begin{abstract}
The aim of this work was to determine the high temperature compression behavior of the solid phase found in a semi-solid 6061 alloy by using an original procedure. A drained compressive test has been carried out to drain the majority of the liquid from the semi-solid alloy and obtain a solid representative of the solid phase of the alloy within the solidification range. The drained compressive tests have shown that the behavior of the semi-solid state is viscoplastic and depends on the initial morphology of the solid skeleton and on the accumulated strain. Then, compressive tests at high temperature have been carried out on drained and non-drained 6061 alloy. Results show that: (1) both alloys exhibit a behavior governed by a hyperbolic sine rheological law, (2) the deformation at high temperature of the drained alloy differs from the deformation of the non-drained 6061 alloy.
\end{abstract}

\section{Introduction}

The rheological behavior of alloys in the solidification range is now studied more and more extensively [1-5] owing to the importance of processes during which solid and liquid phases are coexisting. This coexistence occurs obviously during conventional solidification of castings, ingots or billets but also during liquid phase sintering, welding and forming such as rheocasting or thixocasting [6-10]. The knowledge of this behavior is indeed important for modeling purposes to avoid numerous trial and error experiments. For example, during semi-continuous casting of Al billets, defects like hot tears or macrosegregations [11-13] can form depending on alloy composition and process parameters. Their prediction requires modeling the whole process by considering the behavior of the semi-solid alloy taking into account both the deformation of the solid and the flow of the liquid. Criteria for hot tear formation are then introduced based on critical solid deformation or cavitation pressure in the liquid $[14,15]$.

To determine the rheological behavior of the solid, it is generally assumed that its composition is not far from that of the alloy. Experiments are then carried out at temperatures close to but below the solidus temperature of the alloy to determine the

\footnotetext{
* Corresponding author at: University of Liège, Department A\&M (aeronautics, mechanics and materials), Chemin des chevreuils B52/3, 4000 Liège, Belgium. Tel.: +32 43669110; fax: +32 43669113.

E-mail address: eliane.giraud@ulg.ac.be (E. Giraud).
}

various parameters of the constitutive equation. In this temperature range, viscoplastic behavior is generally a good approximation so that the constitutive equation is mainly determined by the strain rate sensitivity parameter and by the activation energy [16-18]. This procedure therefore does not take into account the fact that the composition of the solid phase is not that of the alloy and also that it is changing with temperature and thus with the solid volume fraction present in the alloy.

Indeed, during solidification or partial melting of a binary alloy, solid and liquid are coexisting with compositions given by the phase diagram and proportions by the lever rule in equilibrium conditions. The composition and the proportion of these two phases thus continuously change with temperature. To determine the constitutive equation of the solid phase, it is therefore necessary to test alloys with various compositions corresponding to those of the solid phase at various temperatures below the solidus. Extrapolation of the results at the solidus temperature for each composition allows determining the behavior of the solid phase in a semi-solid alloy at various temperatures. This procedure can be quite easily considered in the case of a binary alloy but it is hardly possible in a multi-constituent alloy. In this case indeed, the composition of the solid phase is not simply given by the phase diagram and even the solid can be constituted of several phases. Specific softwares are thus required which are able to give the composition and the proportion of the various phases as a function of temperature for various solidification or partial melting conditions. The next step of the procedure would be to prepare alloys with the composition of the solid phase at various temperatures and to test them. 
Another simpler procedure can be considered, i.e. drainage of the liquid from the semi-solid alloy and testing of the remaining solid. If all the liquid present at a given temperature can be drained out of a sample, the remaining solid has the exact composition of the solid phase at this temperature. Repeating this procedure at various temperatures would then lead to various specimens having the composition of the solid phase at these temperatures. One way to carry out this drainage of the liquid is to use drained oedometric compression, already performed on aluminum alloys $[2,19]$. It consists in compressing a semi-solid sample placed in a container with a filter on top of it by applying the compression using a hollow piston to drain the liquid through the filter. This procedure allows one to measure also the compressibility of the solid skeleton provided that the pressure required to drain the liquid is low compared to that required to compress the solid.

In the present work, the feasibility of the procedure exposed above has been studied in the case of a 6061 alloy. Drained compressive tests have been carried out at various temperatures within the solidification range. These tests allow measuring the compressibility of the solid for various temperatures and obtaining specimens representative of the solid phase found in the semi-solid state. Then compressive tests at high temperature (below the solidus temperature) have been carried out on these drained specimens in order to determine the constitutive equation of the solid. Finally, a comparison with the behavior of the non-drained 6061 alloy within the same temperature range has been performed.

\section{Experimental procedure}

The alloy used for this investigation is a 6061 alloy provided by Almet (France) in the form of a rolled plate of $50 \mathrm{~mm}$ thickness in the heat treated T6 condition. In order to drain the liquid from a semi-solid sample, a drained compression apparatus has been designed. It consists in a container of $35 \mathrm{~mm}$ diameter in which the alloy is placed while being still solid (Fig. 1). During the test, the alloy is initially melted, and then partially solidified at a cooling rate of $20 \mathrm{~K} / \mathrm{min}$ until a given solid fraction is reached. At this stage, the temperature is kept constant, and a downward vertical displacement is imposed to the hollow piston. Two displacement rates of the piston have been studied: 0.008 and $0.015 \mathrm{~mm} / \mathrm{s}$. A system of filtration allows the liquid to flow out of the sample, and, consequently, the solid fraction increases. In fact this system is constituted of two different filters as shown in Fig. 1: a rigid stainless steel filter with quite large holes (about $2 \mathrm{~mm}$ diameter) associated with a much thinner stainless steel filter with very small holes (about $200 \mu \mathrm{m}$ diameter). The first filter allows transmitting the load from the hollow piston whereas the second is required for the filtration of the liquid. This test can be seen as a means to impose solidification mechanically at constant temperature. Assuming that the solid fraction evolves only by liquid drainage, the following equation can be used to relate the imposed axial strain $\varepsilon_{z}$ to the solid fraction $g_{s}$ :

$g_{s}=g_{s 0} \exp \left(-\varepsilon_{z}\right)$

where $g_{s 0}$ is the initial solid fraction before any strain is imposed. Two values of this initial solid fraction ( 0.6 and 0.8 ) have been selected by using two temperatures ( $910 \mathrm{~K}$ and $897 \mathrm{~K}$, respectively) at which oedometric compression has been carried out. These two temperatures have been determined by using the ProPhase software (from ALCAN CRV, France). The compression of the sample is pursued until $g_{s}$ is theoretically equal to 1 , which means that all the liquid should have been drained from the semi-solid sample. The test was thus stopped when $\varepsilon_{z}$ satisfied this condition. a
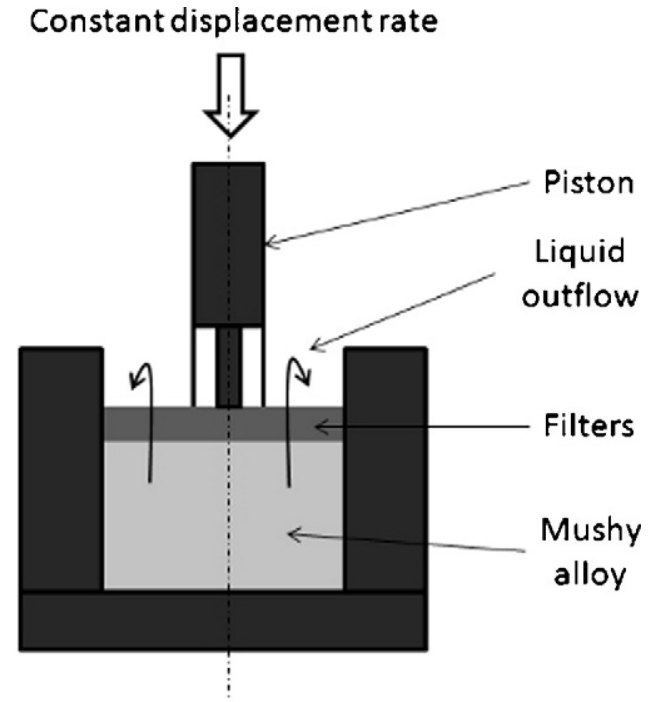

b



Fig. 1. Schematic view of the oedometric compression apparatus (a) with picture of the two filters (b).

After drained compression, the solid remaining in the container has been cut in two pieces through the axis of the cylinder to observe the microstructure of the alloy after drainage of the liquid.

These two pieces have been thereafter machined in order to get compression specimens of $8 \mathrm{~mm}$ in diameter and $6 \mathrm{~mm}$ in height. These specimens have been used for compression tests carried out at high temperature by using the strain rate jump procedure. Four temperatures have been investigated: $723,773,803$ and $823 \mathrm{~K}$ as well as five strain rates: $10^{-4}, 2.5 \times 10^{-4}, 10^{-3}, 2.5 \times 10^{-3}$ and $6 \times 10^{-3} \mathrm{~s}^{-1}$

Similar compression tests have been also carried out for comparison on samples machined in the non-drained 6061 rolled plate.

\section{Experimental results}

\subsection{Drained compression tests}

\subsubsection{Influence of initial solid fraction}

Fig. 2 shows the variation of the applied stress as a function of the theoretical solid fraction (given by Eq. (1)) for the two tests carried out with different initial solid fractions at a displacement rate of the piston of $0.015 \mathrm{~mm} / \mathrm{s}$.

The applied stress obviously increases with increasing strain i.e. with increasing solid fraction. It increases slowly initially when the initial solid fraction is small $(0.60)$ and much more rapidly when the initial solid fraction is larger (0.80). It should be noted that the two curves are coming close to each other at large solid fractions but the curve corresponding to the larger initial solid fraction is always below that for the lower initial solid fraction. In addition, it is surprising to observe that the stress does not increase very sharply when the solid fraction is close to 1 although the solid is not compressible. 




Fig. 2. Variation of the applied stress during drained compression as a function of the solid fraction present in the specimen. The two curves correspond to two different initial solid fractions.

\subsubsection{Influence of displacement rate}

Fig. 3 shows the variation of the applied stress as a function of the solid fraction for the two tests carried out with different displacement rates of the piston and for an initial solid fraction of 0.8 .

The displacement rate has an influence on the stress required to drain the liquid from the specimen: a high strain rate leads to a higher measured stress at a given solid fraction. This strain rate sensitivity is correlated to the viscoplastic behavior of the solid network in this solid fraction range as already observed for tensile [20] and shear [21] experiments.

\subsection{Compressive tests at high temperature (below the solidus temperature)}

\subsubsection{Compressive tests at constant strain rate on drained samples}

Since most of the solidification defects form in the last stage of solidification (i.e. $g_{s}>0.8$ ), only samples machined in the remaining solid obtained after a drained experiment at a high initial solid fraction (i.e. $g_{s 0}=0.8$ ) have been tested in order to determine the high temperature behavior of the solid phase.

Fig. 4 shows the stress-strain curves obtained at the various temperatures and for the different strain rates applied successively from $10^{-4} \mathrm{~s}^{-1}$ to $6 \times 10^{-3} \mathrm{~s}^{-1}$. For a given strain rate, stress increases until a plateau where it remains relatively constant, thus showing negligible strain hardening during deformation of the solid material. Moreover, stress obviously increases with increasing strain rate and decreasing temperature, which highlights the viscoplastic behavior of the solid material.

\subsubsection{Compressive tests at constant strain rate on non-drained 6061 samples}

The same type of compression experiments at various temperatures in the solid state as for drained samples has been performed on non-drained 6061 samples. Fig. 5 shows the stress-strain curves

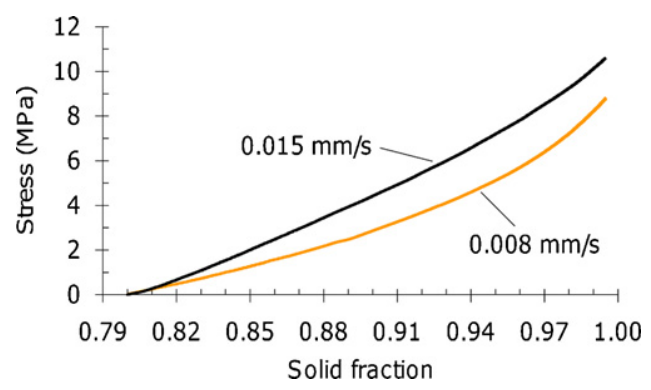

Fig. 3. Variation of the applied stress during drained compression as a function of the solid fraction present in the specimen. The two curves correspond to two different displacement rates of the piston.

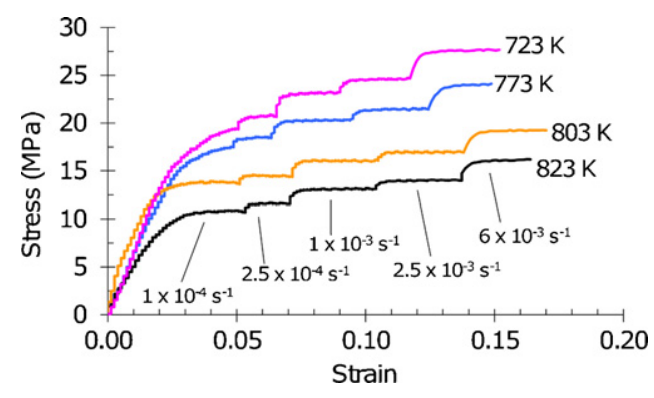

Fig. 4. Stress-strain curves at various temperatures and various strain rates applied by compression on specimens resulting from drained compression of the 6061 alloy at an initial solid fraction of 0.8 .

obtained at the various temperatures and for the different strain rates applied successively from $2.5 \times 10^{-4} \mathrm{~s}^{-1}$ to $6 \times 10^{-3} \mathrm{~s}^{-1}$. Negligible strain hardening and viscoplastic behavior of the solid material are again found.

\section{Discussion}

The behavior of the semi-solid alloy during the drained experiments will be discussed first. Then the behavior observed during compression at high temperature of the solid phase will be examined in order to determine the appropriate rheological law. Finally, a comparison with the behavior at high temperature of the nondrained 6061 alloy will be performed.

\subsection{Behavior of the semi-solid alloy during drained compressive tests}

The stress required for the drained oedometric compression of the partially solidified specimen increases with increasing strain or solid fraction (Figs. 2 and 3). This stress is due to both the densification of the solid skeleton and the liquid flow out of the sample which becomes more and more difficult as the remaining liquid volume fraction decreases. Indeed, a decrease of the liquid volume fraction allows increasing the number of contacts between dendrites and decreasing the interdendritic spaces thus decreasing the permeability of the solid skeleton. Adopting Darcy's law to describe liquid flow and assuming homogeneous deformation in the specimen, its contribution to the stress measured during the drained compression test can be evaluated. The maximal interstitial pressure $P_{L}$, which corresponds to the pressure at the bottom of the container is then given by [22]:

$P_{L}=\frac{V_{p} \cdot \eta}{2 \cdot K \cdot H_{0}} \cdot h^{2}+P_{0}$

where $V_{p}$ is the velocity of the piston, $\eta$ is the liquid viscosity, $K$ is the solid skeleton permeability, $H_{0}$ and $h$ are the initial and current positions of the piston from the bottom of the container and

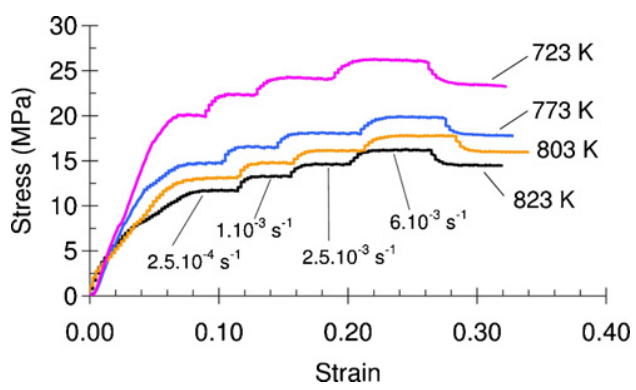

Fig. 5. Stress-strain curves at various temperatures and various strain rates applied by compression on non-drained 6061 specimens. 




Fig. 6. Pressure necessary to drain the liquid through a porous solid medium calculated using Eq. (2).

$P_{0}$ is the pressure due to the drained liquid located above the filters. The variation of the position of the piston during the test is given by: $h=H_{0} \cdot g_{S 0} / 1-g_{L}$ where $g_{S 0}$ is the initial solid fraction and $g_{L}$ is the current liquid fraction. To determine the solid skeleton permeability, the Kozeny-Carman equation can be used $[23,24]$ : $K=g_{L}^{3} \cdot \lambda_{1}^{3} / 5$ where $\lambda_{1}$ is the primary dendrite arm spacing. $\lambda_{1}$ is assumed equal to that given by Flemings for pure aluminum in [25] since, to measure this parameter during our experiments, it would have been necessary to cool with a very high rate the specimen when a solid fraction of 0.8 is reached, which is not possible. $P_{0}$ is given by: $P_{0}=\left(H_{0}-h\right) \cdot \rho_{L} \cdot g$ with $\rho_{L}$ the liquid density and $g$ the gravity acceleration.

The variation of interstitial pressure with liquid fraction, calculated using Eq. (2), is shown in Fig. 6: it increases slowly up to a solid fraction of 0.97 and then very sharply when the solid fraction exceeds 0.97 which corresponds to the coalescence solid fraction $[20,21]$. This sharp increase is due to the fact that, for solid fractions larger than that for coalescence ( $>0.97$ ), the number of solid bridges increases drastically thus leading to a drop of the solid skeleton permeability and then to more and more difficult liquid flow. However, the interstitial pressure remains much lower $(0.07 \mathrm{MPa})$ than the experimental measured stress (12 MPa as shown in Figs. 2 and 3 ) so that it can be neglected during the deformation of the semisolid alloy. The mushy material therefore behaves during drained compression like a solid without liquid.

Metallographic observation of the part of the specimen which has been drained through the filter (Fig. 7) and of the part which remained in the container (Fig. 8) shows that liquid has been effectively drained from the specimen.

The solidified drained liquid (Fig. 7) contains much more eutectic and intermetallics than the non-drained 6061 alloy [20]. Since this liquid was drained from the specimen when the solid fraction was equal to 0.8 , it is possible to determine its composition by using the ProPhase software for the solidification conditions of the experiment $(20 \mathrm{~K} / \mathrm{min}$ ) (Table 1$)$. The liquid is theoretically enriched in
Table 1

Composition (in wt\%) of the liquid in a 6061 alloy when the solid fraction is equal to 0.8 obtained by ProPhase calculation.

\begin{tabular}{llllll}
\hline $\mathrm{Si}$ & $\mathrm{Mg}$ & $\mathrm{Cu}$ & $\mathrm{Fe}$ & $\mathrm{Mn}$ & $\mathrm{Cr}$ \\
\hline 2.5 & 2.9 & 1.1 & 1.2 & 0.2 & 0.06 \\
\hline
\end{tabular}

$\mathrm{Mg}, \mathrm{Si}, \mathrm{Fe}$ and $\mathrm{Cu}$ which are the main secondary elements of the 6061 alloy. An analysis by X-ray diffraction of the drained liquid, by using the $\mathrm{Cu} K \alpha$ radiation, allows detecting various phases which contain these elements such as: $\mathrm{Mg}_{2} \mathrm{Si}, \mathrm{CuAl}_{2}, \mathrm{Al}_{15}(\mathrm{FeMn})_{3} \mathrm{Si}_{2}$ and $\mathrm{Al}_{4} \mathrm{Cu}_{2} \mathrm{Mg}_{8} \mathrm{Si}_{7}$ in addition to the Al-rich matrix (Fig. 9). This result confirms that liquid has been drained from the specimen.

The solid part which remains in the container after drainage contains some intermetallics homogeneously distributed everywhere in the specimen (Fig. 8). Their concentration is not high enough to allow detection by X-ray diffraction: as shown in Fig. 9, only the Al matrix is detected. Since these intermetallics are observed after cooling, it is necessary to wonder whether they were already present in the material before liquid drainage or they formed upon cooling after liquid drainage. Prophase calculation indicates that the first intermetallics form in the 6061 alloy when the volume fraction of the primary phase is 0.84 . Therefore, the intermetallics present in the solid part are more likely to result from the solidification of the liquid which was not drained from the specimen. Thus, the drainage of the liquid has not been complete which seems to be in contradiction with the stress-solid fraction curves (Figs. 2 and 3): these curves indicate that the drained compression tests were stopped when the solid fraction was theoretically very close to 1 , so that almost no liquid should have remained in the specimen. The fact that some liquid remains can be explained by two factors: the filter has been deformed slightly at the end of the compression test so that the real axial strain applied to the specimen was smaller than expected, and/or some solid was extruded through the filter. These assumptions allow us to explain the behavior observed when the apparent solid fraction reaches 1 . Indeed, since the solid is not compressible, the stress should have increased asymptotically to infinite, which is not observed experimentally.

In addition to the viscoplastic behavior of the solid phase shown in Fig. 3, the influence of the initial solid fraction and of the accumulated strain on the mechanical behavior of the semi-solid material has been investigated.

Fig. 2 also shows that stress increases more or less rapidly with increasing strain depending on the initial solid fraction. This is due to the initial morphology of the solid phase: when the initial solid fraction is high, the solid grains are more connected so that drained compression involves extensive deformation of the solid with less rearrangement thus leading to an important increase of stress with increasing strain.
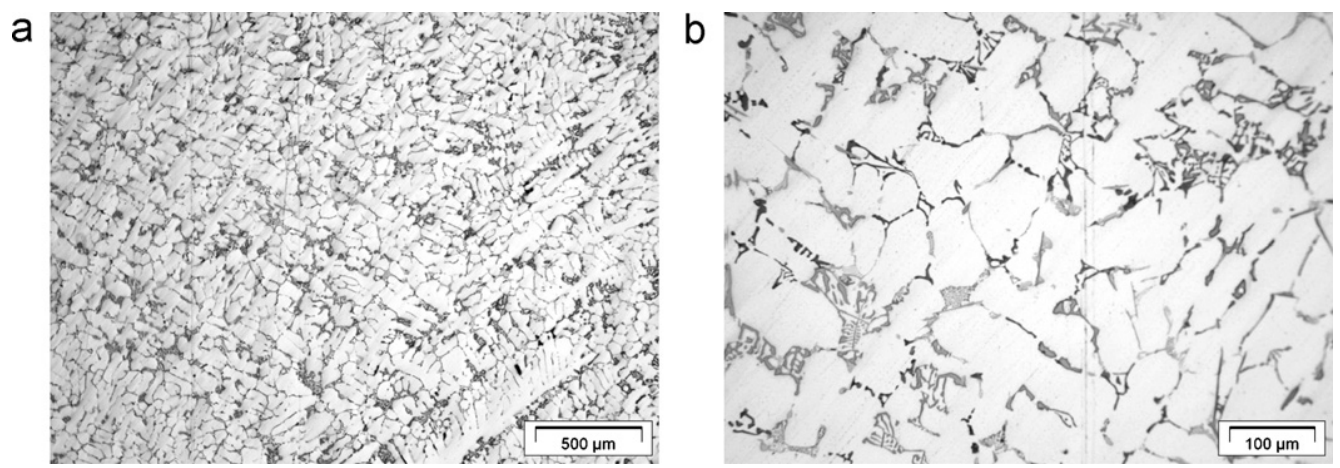

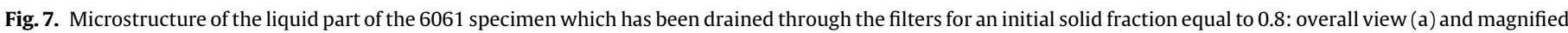
view (b). 

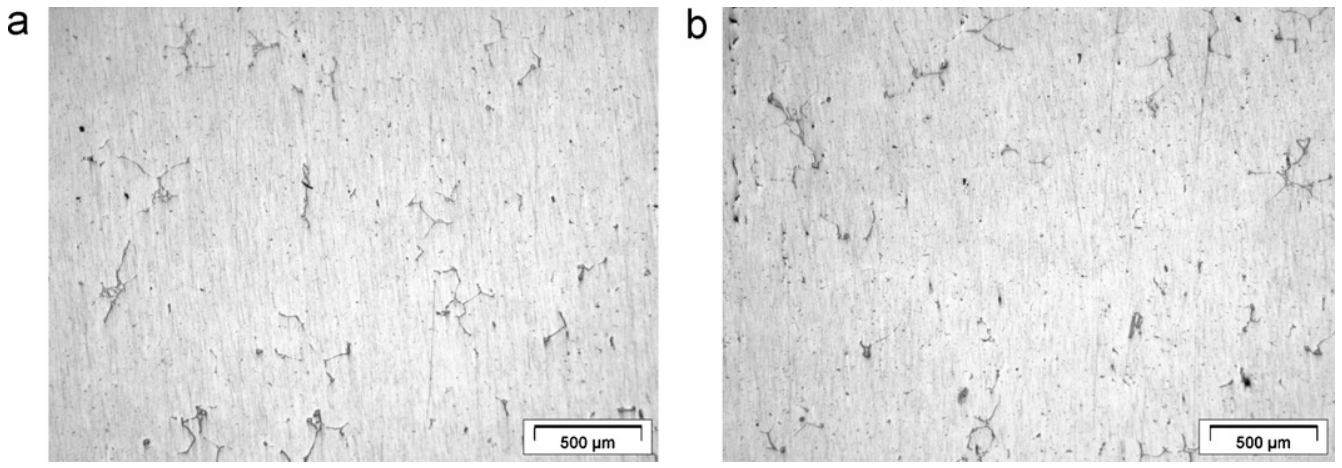

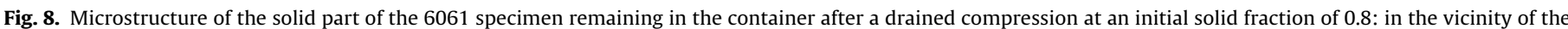
filters (a) and in the bottom of the specimen (b).
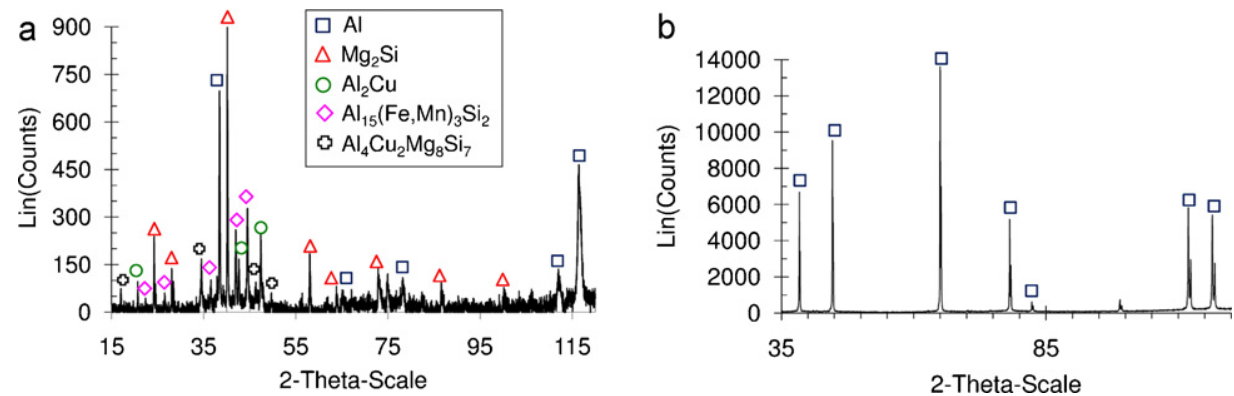

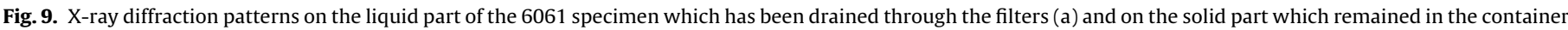
(b) for an initial solid fraction equal to 0.8 .

Fig. 2 shows also that, at a given solid fraction, the measured stress is higher when the initial solid fraction is low. This result can be explained by the level of accumulated strain required to reach this solid fraction, which is larger when the initial solid fraction is low. A larger accumulated strain obviously leads to a more deformed microstructure and consequently to a larger number of solid-solid contacts. However, when the strain is such that the solid fraction approaches 1 , the microstructure is largely deformed with almost no liquid remaining, but, as strain hardening is not observed in this temperature range, the stress no longer depends on the initial solid fraction.

\subsection{Behavior of the drained solid at high temperature}

Fig. 4 has shown that the solid phase exhibits a viscoplastic behavior with negligible strain hardening. The most common approximation used to describe the mechanical behavior of such material consists in using a classical creep law as follows [16,18]:

$\dot{\varepsilon}=A \cdot \sigma^{n} \cdot \exp \left(-\frac{Q}{R T}\right)$

where $\dot{\varepsilon}$ is the strain rate, $\sigma$ is the measured stress, $n$ is the stress sensitivity parameter, $Q$ is the activation energy, $A$ is a material constant, $T$ is the temperature and $R$ is the ideal gas constant.

The behavior of the solid material is thus described by two main parameters: $n$ and $Q$. The slope of the curves showing the variation of stress as a function of strain rate in logarithmic scales (Fig. 10) allows determining the strain rate sensitivity parameter $m$ which is close to 0.08 whatever the temperature. The stress sensitivity parameter $n$ is then equal to $12(n=1 / m)$. From the curves showing the variation of $\ln \left(\dot{\varepsilon} / \sigma^{n}\right)$ as a function of $-1 / R T$ (Fig. 11), it is possible to deduce the activation energy $Q$ which is equal to $347 \mathrm{~kJ} / \mathrm{mol}$.

The values obtained for $n$ and $Q$ are very high. Indeed, as a general rule, the stress sensitivity parameter for materials deformed at high temperature is between 3 and 5 . An exponent of 3 is generally attributed to dislocation glide controlled by viscous drag whereas a value of 5 corresponds to climb controlled dislocation glide [26]. A value of 8 can be sometimes observed when the substructure does not evolve with stress. The activation energy is usually around $130-140 \mathrm{~kJ} / \mathrm{mol}$ which is the activation energy for self-diffusion in

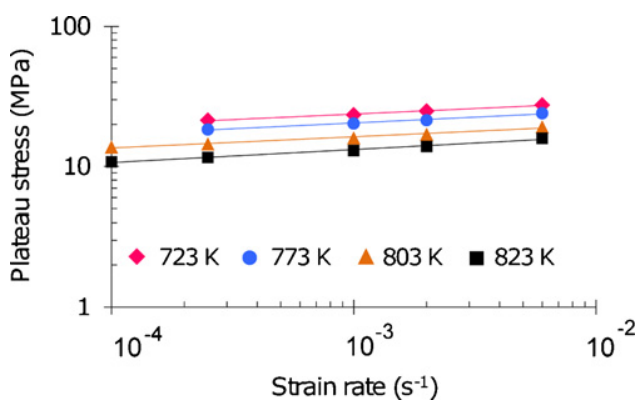

Fig. 10. Stress-strain curves in a logarithmic scale at various temperatures for specimens resulting from drained compression of the 6061 alloy at an initial solid fraction of 0.8 .

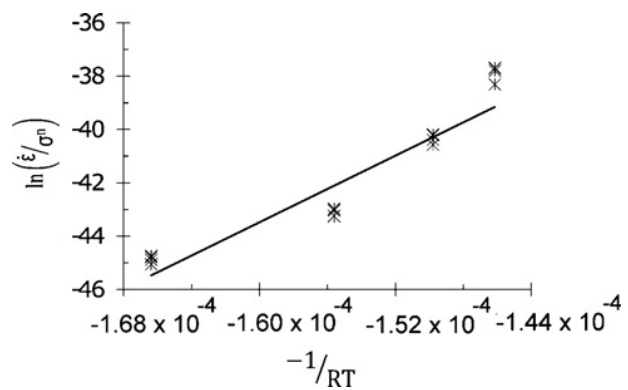

Fig. 11. Determination of the activation energy $Q$ from Eq. (3) for specimens resulting from drained compression of the 6061 alloy at an initial solid fraction of 0.8 . 




Fig. 12. Determination of the material constants A and $\alpha$ from Eq. (4) for specimens resulting from drained compression of the 6061 alloy at an initial solid fraction of 0.8 .

Table 2

Parameters for the rheological law (4) and for specimens resulting from drained compression of the 6061 alloy at an initial solid fraction of 0.8 .

\begin{tabular}{llll}
\hline$n$ & $Q(\mathrm{~kJ} / \mathrm{mol})$ & $\alpha\left(\mathrm{MPa}^{-1}\right)$ & $A\left(\mathrm{~m}^{2} \mathrm{~s}^{-1}\right)$ \\
\hline 5 & 142 & 0.04 & $2 \times 10^{-14}$ \\
\hline
\end{tabular}

aluminum $[27,28]$. Thus, the classical creep law (3) is not adapted to describe the behavior of the solid phase of the 6061 alloy since the values of the various parameters have no physical meaning.

Another possibility consists in using a hyperbolic sine law. Indeed, some alloys can exhibit a stronger stress increase than that predicted by an exponential law when exceeding a given stress or strain rate level [18,29-32]. This leads to the presence of two regimes: a power-law region and a power-law breakdown region, presumably governed by different physical processes not already completely known. For intermediate strain rates and stresses, the alloy exhibits a behavior governed by a power law, whereas, for high strain rates and stresses, a hyperbolic sine law intervenes. Therefore, due to the stress level reached during the experiments, it can be assumed that the experimental conditions lead to the typical behavior of the power-law breakdown regime. In this case, the following equation can be used to relate the strain rate $\dot{\varepsilon}$ to the experimental stress $\sigma[18,29,30]$ :

$\dot{\varepsilon}=\frac{A \cdot G \cdot b}{k \cdot T} \cdot \exp \left(\frac{-Q}{R T}\right) \cdot[\sinh (\alpha \cdot \sigma)]^{n}$

where $b$ is the burgers vector $\left(2.86 \times 10^{-10} \mathrm{~m}\right), k$ is the Boltzman constant $\left(1.38 \times 10^{-23} \mathrm{~J} / \mathrm{K}\right), A$ and $\alpha$ are material constants and $G$ is the shear modulus. It is assumed that the shear modulus depends on temperature according to the equation suggested in [33]: $G=3.022 \times 10^{4}-16 \times T$ (in MPa).

The standard procedure to determine the parameters values can be divided into two main steps: (i) determination of the activation energy $Q$ and the stress sensitivity parameter $n$ by applying Eq. (3) on experimental data within the power-law regime and (ii) determination of the material constants $A$ and $\alpha$ by applying Eq. (4) on experimental data within the power-law breakdown regime and by using the values of $Q$ and $n$ calculated in (i). This procedure assumes that sufficient data for each regime are available, which is not the case in this study. Therefore, the values of $Q$ and $n$ have been fixed to classical values for hot deformation of aluminum alloys [34,35] i.e. $142 \mathrm{~kJ} / \mathrm{mol}$ and 5, respectively. Parameter's and material's constants $A$ and $\alpha$ have then been determined so that the variation of $\dot{\varepsilon} \cdot k \cdot T \cdot \exp (Q / R T) / G \cdot b$ as a function of $\sinh (\alpha \cdot \sigma)$ in a logarithmic scale exhibits a slope equal to 5 , as shown in Fig. 12 . The values of the different parameters of Eq. (4) are summarized in Table 2. It can be noticed that the material constant $\alpha$ is in agreement with classical values of the literature for aluminum alloys: from 0.01 to $0.08[29-31,36]$, which tends to show that a hyperbolic sine law is
Table 3

Parameters for the rheological law (4) and for non-drained 6061 specimens.

\begin{tabular}{llll}
\hline$n$ & $Q(\mathrm{~kJ} / \mathrm{mol})$ & $\alpha\left(\mathrm{MPa}^{-1}\right)$ & $A\left(\mathrm{~m}^{2} \mathrm{~s}^{-1}\right)$ \\
\hline 5 & 142 & 0.055 & $6 \times 10^{-15}$ \\
\hline
\end{tabular}

relatively appropriate to describe the behavior of the solid phase of the 6061 alloy.

\subsection{Comparison with the behavior at high temperature of the non-drained 6061 alloy}

The same study as for the drained alloy has been performed on the 6061 alloy in order to determine the most appropriate rheological law describing its behavior at high temperature.

Since Eq. (3) still leads to high values for the activation energy $Q$ (about $287 \mathrm{~kJ} / \mathrm{mol}$ ) and the stress sensitivity parameter (about 11), an identical procedure has been followed to estimate the values of the parameters for Eq. (4). These values are summarized in Table 3.

Although the behavior of the non-drained 6061 alloy is also governed by a hyperbolic sine law, it can be noticed, by comparing Tables 2 and 3 , that the values of the constitutive parameters are different depending on the type of tested material. Therefore, the deformation at high temperature of the non-drained 6061 alloy differs from the deformation of the drained alloy, which confirms the necessity to study the behavior of the material with the appropriate composition to determine the response of the solid phase in the semi-solid state.

\section{Conclusion}

In this study, an original technique to determine the behavior at high temperature of the solid phase of a multi-constituent alloy was presented. It consists in: (i) drainage of the liquid present at a given temperature in order to obtain a solid with the exact composition of the solid phase at this temperature and (ii) deformation of the solid at high temperature to determine the rheological law.

The densification behavior of the 6061 alloy in the mushy state has been investigated thanks to drained compressive tests. These tests consist in a mechanical solidification of the semi-solid alloy at a constant temperature resulting from liquid drainage through filters which leads to a nearly complete densification of the solid phase. The results have shown that the compression behavior of the semi-solid alloy depends on strain rate, on the initial morphology of the solid skeleton and on the accumulated strain. Indeed, at a given solid fraction achieved during compression, the pressure required to densify the solid increases with decreasing initial solid fraction and thus increasing accumulated strain. Since strain hardening is not present in this temperature range, this result is correlated to the liquid distribution in the specimen which depends on the accumulated strain.

Specimens resulting from drained compression have been further tested in simple compression at high temperature to determine the constitutive equation of the solid phase present in a semi-solid 6061 alloy at a given temperature and to compare it with that of the 6061 alloy. Compression tests with strain rate jumps at various temperatures have shown that the behavior of the two materials is governed by a hyperbolic sine law. The values of the parameters of the constitutive equation are however different. This thus shows that the behavior of the solid phase in the 6061 alloy differs from that of the alloy. It is therefore necessary to study the behavior of the material with the appropriate composition if the behavior of the solid phase must be known within the solidification range. 


\section{Acknowledgements}

One of the authors (EG) is grateful to CNRS (French National Center for Scientific Research) and AREVA for financial support through a scholarship. The authors thank Cédric Gasquères, ALCAN CRV (France), for providing the ProPhase calculations and Stéphane Coindeau, CMTC (France), for the analysis by X-ray diffraction.

\section{References}

[1] A.K. Dahle, D.H. StJohn, Acta Mater. 47 (1998) 31-41.

[2] O. Ludwig, J.M. Drezet, P. Ménésès, C.L. Martin, M. Suéry, Mater. Sci. Eng. A 413-414 (2005) 174-179.

[3] D. Brabazon, D.J. Browne, A.J. Carr, Mater Sci. Eng. A 356 (2003) 69-80.

[4] Y. Zhu, J. Tang, Y. Xiong, Z. Wu, C. Wang, D. Zeng, Sci Technol. Adv. Mater. 2 (2001) 219-223.

[5] O. Lashkari, R. Ghomashchi, J. Mater. Process. Technol. 182 (2007) 229-240.

[6] T. Haga, S. Suzuki, J. Mater. Process. Technol. 118 (2001) 169-172.

[7] B. Hu, I.M. Richardson, Mater. Sci. Eng. A 429 (2006) 287-294.

[8] T. Haga, P. Kapranos, J. Mater. Process. Technol. 130-131 (2002) 594-598.

[9] P. Falak, B. Niroumand, Scripta Mater. 53 (1) (2005) 53-57.

[10] M. Paes, E.J. Zoqui, Mater. Sci. Eng. A 406 (2005) 63-73.

[11] Suyitno, D.G. Eskin, L. Katgerman, Mater. Sci. Eng. A 420 (2006) 1-7.

[12] H. Nagaumi, T. Umeda, J. Light Metals 2 (2002) 161-167.

[13] R. Nadella, D.G. Eskin, Q. Du, L. Katgerman, Mater. Sci. Eng. A 420 (2006) 1-7.
[14] B. Magnin, L. Maenner, L. Katgerman, S. Engler, Mater. Sci. Forum 217-222 (1996) 1209-1214

[15] M. Rappaz, J.M. Drezet, M. Gremaud, Metall. Mater. Trans. A 30 (1999) 449-455.

[16] H.J. McQueen, Metall. Mater. Trans. A 33 (2002) 345-362.

[17] M.E. Kassner, M.T. Perez-Prado, Prog. Mater. Sci. 45 (2000) 1-102.

[18] F.R.N. Nabarro, Acta Mater. 54 (2006) 263-295.

[19] O. Ludwig, C.L. Martin, M. Suéry, Mater. Sci. Forum 396-402 (2002) 265-270.

[20] E. Giraud, M. Suéry, M. Coret, Metall. Mater. Trans. A 41 (2010) 2257-2268.

[21] E. Giraud, M. Suéry, M. Coret, Metall. Mater. Trans. A 42 (2011) 3370-3377.

[22] T.G. Nguyen, D. Favier, M. Suéry, Int. J. Plasticity 10 (1994) 663-693.

[23] O. Nielsen, L. Arnberg, A. Mo, H. Thevik, Metall. Mater. Trans. A 30 (1999) 2455-2462.

[24] S.G.R. Brown, J.A. Spittle, D.J. Jarvis, R. Walden-Bevan, Acta Mater. 50 (2002) 1559-1569.

[25] M.C. Flemings, Solidification Processing, McGraw-Hill Inc., New York, 1974.

[26] L. Kloc, S. Spigarelli, E. Cerri, E. Evangelista, T.G. Langdon, Acta Mater. 45 (1997) 529-540.

[27] B.S. Bokstein, Mater. Sci. Forum 217-222 (1996) 685-688.

[28] X. Doré, H. Combeau, M. Rappaz, Acta Mater. 48 (2000) 6951-6962.

[29] H.J. McQueen, E. Fry, J. Belling, J. Mater. Eng. Perform. 10 (2001) 164-172.

[30] M.S. Soliman, J. Mater. Sci. 22 (1987) 3529-3532.

[31] S. Spigarelli, E. Evangelista, H.J. McQueen, Scripta Mater. 49 (2003) 179-183.

[32] E.A. El-Danaf, A.A. AlMajid, M.S. Soliman, J. Mater. Eng. Perform. 17 (2008) 572-579.

[33] E.A. El-Danaf, A.A. AlMajid, M.S. Soliman, J. Mater. Sci. 43 (2008) 6324-6330.

[34] K. Park, E.J. Lavernia, F.A. Mohamed, Acta Metall. Mater. 42 (1994) 667-678.

[35] R. Fernandez, G. Gonzales-Doncel, J. Alloys Compd. 440 (2007) 158-167.

[36] G. Chunlei, X. Yongdong, W. Mengjun, Mater. Sci. Eng. A 528 (2011) 4199-4203. 